\title{
DISPERSÃO DA COVID-19 NO ESTADO DO PARANÁ
}

\section{DISPERSION OF COVID-19 IN THE STATE OF PARANÁ}

Oseias da Silva Martinuci Docente do Programa de Pós-Graduação em Geografia Universidade Estadual de Maringá/PR osmartinuci@uem.br

Valéria Lima

Docente do Departamento de Geografia Universidade Estadual de Maringá/PR vlima@uem.br

Ângela Maria Endlich Docente do Departamento de Geografia Universidade Estadual de Maringá/PR amendlich@uem.br

Otávio Cristiano Montanher Discente do Programa de Pós-Graduação em Geografia Universidade Estadual de Maringá/PR otaviocmontanher@yahoo.com.br

Matheus Grochoski Felini Discente do Programa de Pós-Graduação em Geografia Universidade Estadual de Maringá/PR mateusgrochoskifelini@gmail.com

Kelly Cristina Rigoldi Discente do Curso de Geografia Universidade Estadual de Maringá/PR

kellyrigoldi@gmail.com

Laine Milene Caraminan Discente do Curso de Geografia Universidade Estadual de Maringá/PR caraminanlaine@gmail.com

Rafael Balieiro Crestani Discente do Curso de Geografia Universidade Estadual de Maringá/PR rafaelgeopolitica@gmail.com

Rodrigo Blaudt Lima da Silva

Discente do Curso de Geografia Universidade Estadual de Maringá/PR rodrigo.blaudt@outlook.com

Gabriel Henrique Sorato da Silva

Discente do Curso de Geografia Universidade Estadual de Maringá/PR gabrielsorato29@gmail.com

Monique Rafaela Ferreira Discente do Curso de Geografia Universidade Estadual de Maringá/PR moniquerafaela53@gmail.com

Recebido em: 10/05/2020

Aceito para publicação em: 21/05/2020. 


\begin{abstract}
RESUMO
O presente texto tem como objetivo apresentar análise do processo de difusão espacial da Sars-Cov-2 (Severe Acute Respiratory Syndrome Coronavirus 2), também conhecida como Covid-19 ou Coronavirus, no estado do Paraná. Para tanto, a análise dos dados é focada no primeiro mês após a confirmação do primeiro caso, ocorrido no dia 12 de março de 2020. Subjacente à análise está a compreensão de que a Covid-19, como um evento de saúde pública de interesse mundial, está atrelada às estruturas e dinâmicas do espaço geográfico. Dialeticamente, como singularidade e universalidade, simultaneamente faz parte do espaço geográfico, mas, também, é espaço geográfico. Metodologicamente, são considerados: 1) dados produzidos pelas Secretarias Municipais e Estaduais de Saúde; 2) dados sobre Síndromes Respiratórias Agudas Graves do sistema Sivep-Gripe do Ministério da Saúde; 3) dados demográficos, de infraestruturas e organização do território do Instituto Brasileiro de Geografia e Estatística (IBGE); 4) dados do Cadastro Nacional de Estabelecimentos de Saúde (CNES). A partir da análise conjunta dos dados, subsidiada pela teoria da produção do espaço geográfico, foi possível chegar a algumas constatações: a) a dispersão do vírus pelo território se dá em dependência com as estruturas e dinâmicas territoriais; b) os pontos e rotas predominantes são as cidades médias e eixos rodoviários economicamente mais importantes que constituição basicamente em espaços de contágio e de dispersão; c) cidades médias são espaços estratégicos de contensão ou de aceleração da dispersão, pois as decisões nelas tomadas determinarão os impactos nas cidades pequenas sob sua influência; d) as cidades pequenas, que ainda não foram significativamente afetadas, têm redes de atenção à saúde muito frágeis, o que permite antever cenários de grande risco para as populações que nelas residem. A análise geográfica, por fim, pode dar uma dupla contribuição: reconhecer os padrões espaciais das rotas de dispersão, fornecendo informações relevantes para o planejamento das ações em saúde, por um lado, e aprofundar a compreensão dos modos de ser do espaço geográfico contemporâneo, através dos eventos em saúde, por outro.
\end{abstract}

Palavras-chave: Geografia. Covid-19. Paraná. Brasil.

\title{
INTRODUÇÃO
}

O mundo enfrenta uma pandemia global sem precedentes na história. A Sars-Cov-2 (Severe Acute Respiratory Syndrome Coronavirus 2), que ficou conhecida como Covid-19 ou Coronavirus, teve seu primeiro caso na China, em dezembro de 2019, e rapidamente chegou a todos os continentes e à maioria dos países. Apesar dos vários estudos, desenvolvidos em curto espaço de tempo, desde que a doença surgiu, ainda se sabe pouco de sua história natural. Pesquisas em biomedicina e testes farmacológicos estão sendo desenvolvidos, mas ainda não há nenhum resultado conclusivo. Baseadas nos modelos epidemiológicos, as análises estatísticas, por sua vez, sustentam que a medida de saúde pública mais eficiente até o momento é o distanciamento social. O Boletim Epidemiológico 07 do Ministério da Saúde do Brasil (2020) identificou que a taxa de transmissibilidade, ou seja, o número médio de contágios causado por cada pessoa infectada, aquilo que os epidemiologistas chamam de R0 ("R zero"), é reduzida após a adoção de medidas de distanciamento social ampliado.

As análises que têm sido feitas por pesquisadores de diversas áreas do conhecimento atestam que o Covid-19 se dissemina mais rapidamente conforme a intensidade do contato entre pessoas. Dito de outro modo, a intensidade da circulação no território condiciona fortemente a velocidade de disseminação do vírus. Tecnicamente, significa dizer que a taxa de transmissibilidade varia em proporção à circulação de pessoas. Assim, espaços de maiores densidades econômicas, demográficas e de fluxos estão mais suscetíveis à dispersão do vírus. 
O vírus entrou no Brasil, possivelmente ainda no mês de fevereiro. O primeiro caso confirmado se deu no dia 26 de fevereiro, exatamente na cidade de São Paulo, o principal ponto de conexão do Brasil com o mundo. A partir, essencialmente, da capital paulista, o Covid-19 começa, já no mês de março, a se espalhar pelo interior do território brasileiro.

Nesse contexto e ainda no calor dos acontecimentos, o presente texto, objetiva apresentar uma caracterização inicial do processo de difusão do vírus no estado do Paraná. Para isso, realizamos, em primeiro lugar, uma breve discussão sobre o papel da Geografia no estudo dos eventos em saúde. Num segundo momento, caracterizamos o processo de difusão do Covid-19 do Paraná, destacando o momento inicial: 1) a origem dos casos importados; 2) a localização dos primeiros casos no primeiro mês; 3 ) as principais rotas e pontos de dispersão; 4) a velocidade de dispersão, comparativamente a outras unidades da federação. Em seguida, analisamos a situação epidêmica de acordo com as macrorregiões de saúde, levando em consideração: 1) a rede assistencial, especialmente, os leitos de UTI e respiradores; 2) os casos confirmados de Covid-19; 3) possíveis impactos em pequenos municípios.

\section{A LEITURA GEOGRÁFICA DOS EVENTOS DE SAÚDE}

A Geografia pode, a um só tempo, contribuir para uma compreensão teórica das relações entre espaço e saúde e fornecer instrumentos para dar suporte à tomada de decisões. O reconhecimento das estruturas socioespaciais (infraestrutura de transportes, padrões de circulação, hierarquias urbanas, padrões etários espaciais, distribuição de comorbidades, localização e perfil dos recursos para assistência à saúde nas cidades e nas regiões) decorrentes do uso do território, portanto, é fundamental para a realização de prognósticos e para subsidiar ações emergenciais, especialmente quanto à alocação de recursos e ampliação da rede assistencial em face do Covid-19.

Para Milton Santos (2004), cada lugar e cada fenômeno tem um significado particular, mas esse significado não pode ser apreendido senão no nível da totalidade. É na relação entre particulares que cada coisa no mundo ganha sentido. A saúde é um desses fenômenos que exige compreensão no nível da totalidade.

A natureza atual do espaço geográfico, denominado por Milton Santos (2002) como meio técnicocientífico-informacional, nos autoriza ver a saúde como um fenômeno de múltiplas relações (dimensionais e escalares), a ponto de podermos afirmá-la como um fenômeno geográfico. Diríamos mais: é, ela mesma, espaço geográfico. A saúde é a síntese de um conjunto amplo de eventos que se manifestam como forma e como norma, como materialidade e como ação. Com isso queremos dizer que ela não se faz isoladamente, mas com uma série de conexões que nos obrigam a uma permanente referência ao biológico, ao social, ao econômico, à política, ao território e às escalas.

A saúde não se descola hoje do movimento do mundo, sendo ela um elemento do espaço total e uma totalidade, ao mesmo tempo (MARTINUCI, 2019). Poderíamos ir mais adiante e afirmar a saúde como um ponto interessante de partida que nos ajuda a compreender a interdependência das coisas no mundo e a existência como totalidade. A pandemia da Covid-19 que assolou o mundo no início do ano de 2020, é um claro exemplo disso. Ela se mostrou estreitamente associada à dinâmica econômica, ao processo de globalização, se difundindo rapidamente pelo mundo através das redes de mobilidade humana, primeiramente aeroviárias e logo em seguida, rodoviárias.

Adicionalmente, as ferramentas tecnológicas de geoprocessamento, aliadas ao conhecimento geográfico das características espaciais (forma, função, processo e estrutura) (SANTOS, 1985), são indispensáveis à gestão de processos infecciosos altamente condicionados pela organização territorial em tempos de globalização.

Convém lembrar que o raciocínio espacial mais elementar foi essencial para o médico inglês John Snow deter o surto de cólera na Londres de 1854 (SNOW, 1999), correlacionando variáveis espaciais. Isso Ihe permitiu não somente resolver, pragmaticamente, o problema imediato de saúde pública, mas também revolucionar a abordagem epidemiológica vigente naquele momento. O mundo DOl:http://dx.doi.org/ 10.14393/Hygeia0054619 Hygeia Edição Especial: Covid-19, Jun./2020 p.251 - 262, pág.253 
hoje se tornou muito mais complexo que em meados do século XIX e, consequentemente, os eventos em saúde que exigem, para seu estudo, um elenco numeroso de variáveis. $O$ avanço das geotecnologias, entretanto, tem dado grande suporte à tarefa de análise, sendo um primeiro passo necessário, ainda que insuficiente. Apesar de extraordinárias, elas são apenas ferramentas. É fundamental, antes delas e depois delas, o suporte de um modelo explicativo da produção do espaço geográfico (SANTOS, 2000) para o reconhecimento das características sociais, econômicas, epidemiológicas e infraestruturais dos territórios e suas consequentes interações.

Portanto, é possível afirmar, a partir dessa linha de raciocínio, que a saúde não pode ser compreendida integralmente sem a consideração do espaço geográfico. $\mathrm{Na}$ era do chamado meiotécnico-científico-informacional, num mundo altamente conectado por redes de todo tipo (comunicação, circulação etc.), eventos de saúde como a pandemia do Covid-19 podem se difundir com muita rapidez, fortemente condicionados pelas estruturas preexistentes no território, que modulam direção e intensidade.

Em meio a processos epidêmicos e pandêmicos, como a Covid-19, é essencial identificar nos territórios, por exemplo, os centros urbanos economicamente mais importantes e os eixos de circulação mais vigorosos, pois, por uma série de razões, constituem-se nos espaços preferenciais de disseminação de vírus. O que acontecer nesses espaços terá, logo em seguida, repercussões nas suas regiões imediatas de influência. Nesse contexto, é imprescindível avaliar regionalmente as demandas de saúde e a rede assistencial, pois a maior parte dos pequenos municípios que orbitam em torno de centros urbanos regionais, não possuem nem mesmo os recursos mais básicos de saúde.

O modo como o território se organiza, como os recursos sociais, econômicos, infraestruturais e tecnológicos estão distribuídos no território, condicionam sobremaneira os modos de se obter saúde e, por extensão, de ter uma vida mais longa. A Geografia é indispensável no entendimento e apoio aos processos de difusão de doenças infecciosas.

A análise da dispersão da Covid-19 pelo interior do país, nesse momento, portanto, é essencial. Este texto, particularmente, objetiva expor o processo de difusão espacial do Covid-19 no estado do Paraná.

\section{MÉTODO E METODOLOGIA}

A análise da difusão espacial do Covid-19 no estado do Paraná parte de um pressuposto de método: que os eventos singulares sejam elas quais forem, encontram seu sentido e, consequentemente, sua explicação, na totalidade da qual, dialeticamente, faz parte. Contudo, essa totalidade, ao mesmo tempo, só aparece ao pesquisador, como algo a ser analisado, quando se geografiza. O que ocorre por meio do evento singular. Assim, acessamos o sentido das coisas somente através dos eventos que se revelam apenas parcialmente, como falso concreto. Essa condição pode ser superada por meio da análise dos objetos de estudo, indo para além do objeto imediato, chegando à apreensão de um tipo superior, o "concreto pensado" (LUKACS, 2018).

Em outras palavras, significa reconectar, a partir do pensamento, a fração do mundo (o singular) com a totalidade (o universal), através de uma categoria mediadora, aquilo que condiciona os modos de ser do evento singular (particularidade). Há, portanto, nesse texto, uma compreensão dialética singular-universal-particular.

Nessa acepção é que podemos compreender a Covid-19 como um evento da saúde, mas também, simultaneamente, como espaço geográfico, tendo suas características moldadas pelas formas e processos espaciais.

Como um primeiro exercício de aproximação, tomando esses fundamentos como referência foram realizadas, basicamente: 1) análise dos dados e informações sobre o Covid-19; 2) correlação com infraestruturas de circulação e formas de organização do território. 
Esses dados são apresentados na forma de mapas e gráficos. Para fins de análise, levamos em consideração, as escalas do estado e das macrorregiões de saúde.

As fontes de dados constituem-se, basicamente, nas pesquisas do Instituto Brasileiro de Geografia e Estatística (IBGE), nos dados do Ministério da Saúde e das Secretarias Estaduais de Saúde.

\section{A DISPERSÃO DO COVID-19 NO ESTADO DO PR}

Dezessete dias após a confirmação do primeiro caso de Covid-19 no Brasil, o estado do Paraná registrou seus primeiros casos, simultaneamente em Curitiba, capital do estado, e em Cianorte, cidade da região noroeste com pouco mais de 80 mil habitantes. Em ambos os casos, a contaminação ocorreu no exterior, tendo como ponto de acesso os aeroportos. Os fluxos aéreos com o exterior fizeram das cidades médias (SPOSITO, 2007) as portas de interiorização do vírus. Nessas cidades, a contaminação foi registrada de forma independente da transmissão comunitária, ou seja, os casos foram importados diretamente do exterior.

Os casos confirmados na primeira semana no estado do Paraná, entre os dias 12 e 16 de março, foram importados da Europa e da Ásia (Figura 1).

Figura 1 - Paraná: origem dos casos de Covid-19 entre 12/03 e 26/03/2020

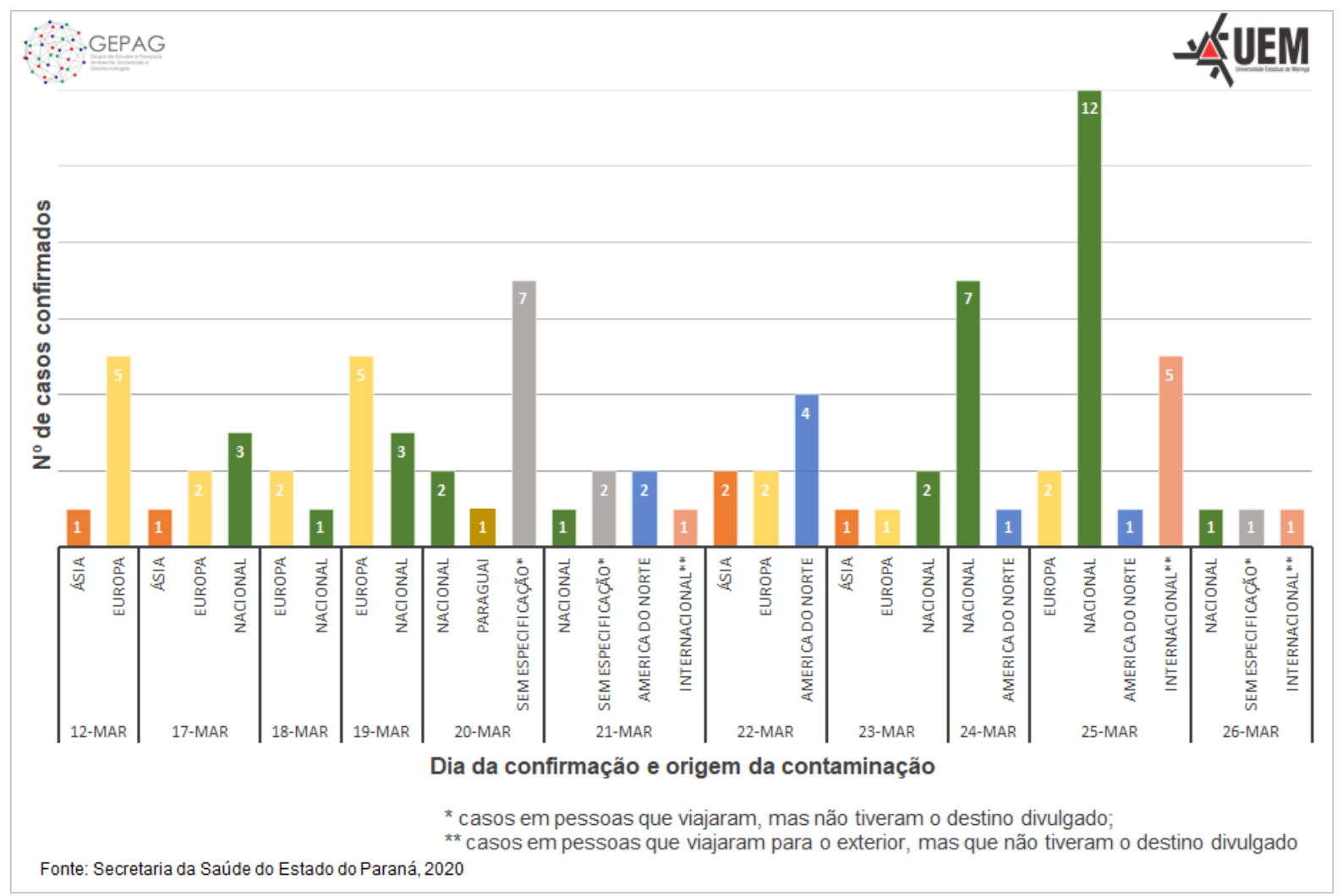

Elaboração: Autores, 2020

Até o dia 19 de março, a maioria das pessoas diagnosticadas com Covid-19 haviam viajado recentemente ao exterior, principalmente para a Europa. Naquele momento, a Europa era a principal 
região de contaminação. Já a partir da segunda semana, mais precisamente do dia 24 de março, passaram a se avolumar os casos de contaminação decorrentes da circulação no território nacional.

Desde já, podemos fazer duas constatações: 1) a entrada do Covid-19 no estado do Paraná se deu através de casos importados diretamente do exterior; 2) os principais pontos de contaminação são aqueles onde estão localizados os principais aeroportos, ou seja, os polos econômicos mais dinâmicos, que chamaremos aqui de cidades médias em conformidade com a abordagem de Sposito (2007).

Interessa saber, agora, como se deu a difusão dos casos pelo estado. Para isso, realizamos o mapeamento (Figura 2) dos primeiros casos para identificar a constituição de eixos de propagação e/ou focos de difusão.

Como pode ser percebido na Figura 2, a maior quantidade de casos, no primeiro mês, estava localizada na cidade de Curitiba. Ali a transmissão comunitária já estava curso, com uma grande quantidade de casos nas cidades que compõem a Região Metropolitana de Curitiba. A transmissão comunitária, significa, em termos espaciais, que a contaminação dos vírus já opera na contiguidade, ou seja, por vizinhança, e não somente de modo hierárquico, ou seja, por importação de outros países ou estados.

Figura 2 - Difusão espacial da Covid-19 no estado do Paraná: 12/03 a 12/04/2020

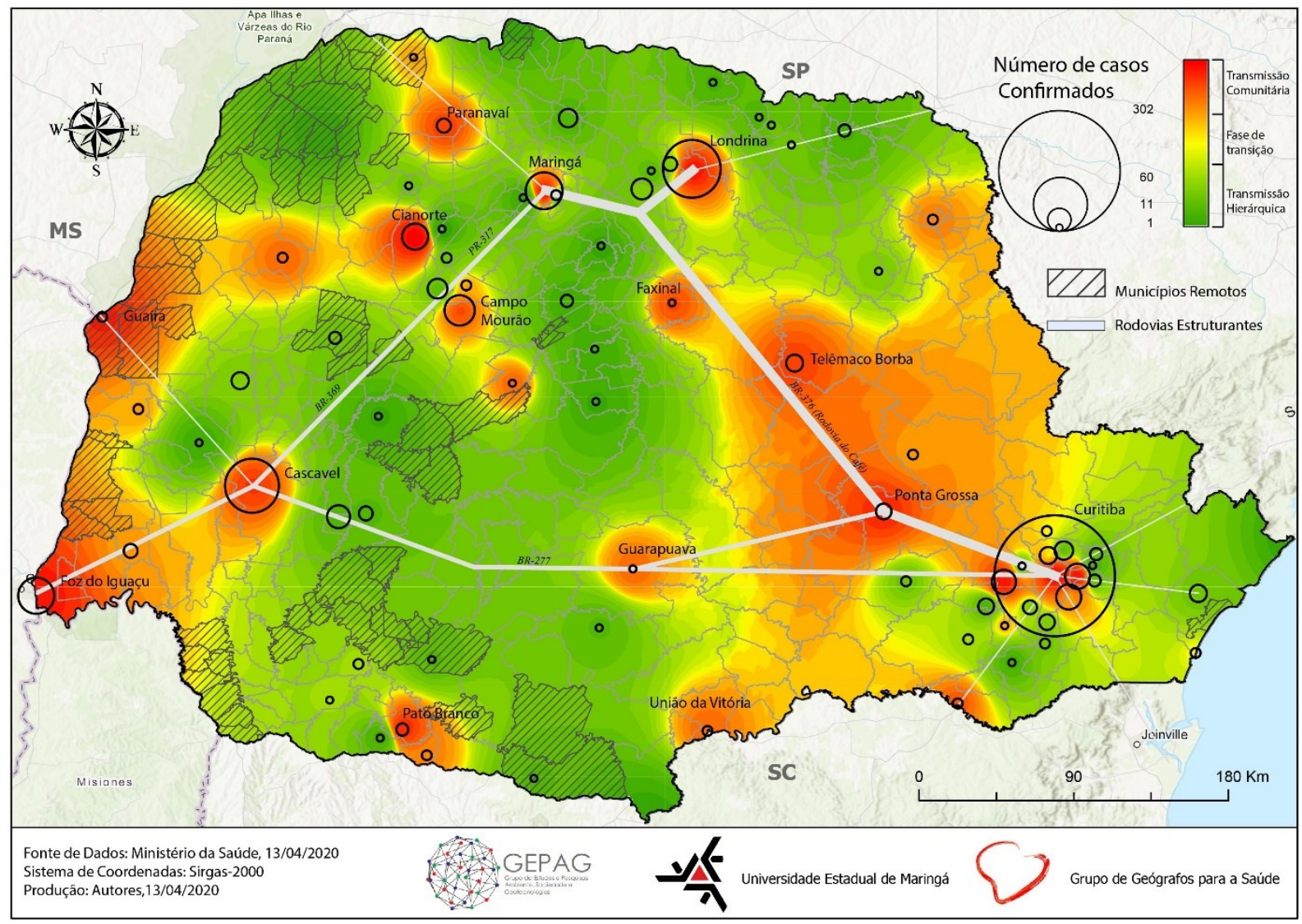

Elaboração: autores, 2020 
O segundo foco de atenção corresponde à região Noroeste, onde já havia uma grande quantidade de municípios contaminados. Nessa região, uma das mais dinâmicas e urbanizadas do estado, estão localizadas as duas maiores cidades do interior, Londrina e Maringá, que, de acordo com projeções do IBGE, possuíam em 2019, respectivamente, populações de 570 mil e 423 mil habitantes. Por fim, há vários municípios na região Oeste, que desde cedo tiveram registros de casos confirmados, tendo já a partir da terceira semana, iniciado processo de transmissão comunitária.

Como pode ser visto no mapa (Figura 2), essas regiões e cidades estão conectadas pelo conhecido Anel Viário (BR-369, PR-317, BR-376 e BR-277), composto por rodovias estaduais e federais. A representação sugere, inicialmente, a conformação de um eixo de propagação do vírus ao logo da chamada "Rodovia do Café" (BR-376), que liga a Região Metropolitana de Curitiba ao norte do Estado, mais especificamente à Londrina e à Maringá. Sinteticamente, a representação dos casos no primeiro mês indicou três áreas de interesse epidemiológico: 1) áreas de "transmissão hierárquica" (áreas em tons de verde), onde os casos ainda eram muito recentes ou ainda não tinham sido registrados, estando sujeitos a importação de outras localidades; 2) áreas de "transmissão comunitária" (áreas mais vermelhas dos mapas), onde o vírus já havia se instalado e circulava entre a população, e; 3) áreas em "fase de transição" (áreas amarelas e laranjas), que correspondiam a áreas com municípios ou que registraram recentemente o primeiro caso, ou que são vizinhas a municípios contaminados.

Essa representação é fundamental pois indica com muita clareza que as áreas mais dinâmicas do território, que estão conectadas por redes de circulação terrestre ou aérea, são as portas de interiorização das doenças altamente contagiosas, num primeiro momento, e ponto de dispersão, num segundo momento. Em processos pandêmicos como o da Covid-19, planos de ação para contenção da circulação viral devem dar especial atenção aos pontos vermelhos do mapa.

A Covid-19, portanto, é uma expressão clara de como os processos de saúde ocorrem estreitamente ancorados na estrutura territorial preexistente. As características do processo de dispersão no estado do Paraná são resultado e síntese de uma multiplicidade de fatores que encontram seus fundamentos na produção do espaço em escala global, mas que tem suas condições de realização estabelecidas em situações territoriais concretas. Vê-se como a estrutura territorial regional (sistema de transportes aeroviários e rodoviários e a organização e hierarquia urbana) define direção e magnitude desse evento de saúde em particular.

Comparativamente ao estado de São Paulo, onde foi confirmado o primeiro caso de Covid-19, nas primeiras quatro semanas, houve maior velocidade na contaminação dos municípios. Como pode ser constatado na Figura 3, no estado do Paraná, ao final da quarta semana, depois da confirmação do primeiro caso, o número de municípios contaminados era quatro vezes mais alto que no estado de São Paulo. Enquanto no território paulista eram 18, no Paraná eram 73. Uma explicação possível pode ser: enquanto a porta de entrada do vírus em São Paulo foi basicamente, a capital, no Paraná teve, simultaneamente, várias portas de entrada, as suas cidades médias.

Apesar da maior velocidade de dispersão do vírus pelo território paranaense ainda é preciso considerar a grande subnotificação. Levar em consideração as notificações por Síndromes Respiratórias Agudas Graves (SRAG) tem sido uma estratégia assumida pelos pesquisadores como uma proxy do nível de contaminação pela Covid-19. Ao analisar os dados do Paraná referente ao período de 12 de março e 12 de abril, desde o ano de 2010 (Figura 4), notamos uma grande diferença entre a média de notificações dos anos anteriores e as notificações de 2020.

Os pontos fora das linhas-limite do gráfico indicam os outliers, ou seja, valores discrepantes da série temporal. Os dois casos do gráfico representam eventos de saúde singulares: o mais próximo do limite superior, está relacionado com o vírus Influenza (H1N1) em 2010 e o mais distante se refere aos dados de Síndrome Respiratória Aguda Grave (SRAG) em 2020, indicando, possivelmente, os impactos da Covid-19. Enquanto a média da série dos anos anteriores foi de 429, no período de 12 de março a 12 de abril de 2020 os registros totalizaram 2.444, ou seja, 5,7 vezes mais. 
Oseias da Silva Martinuci

Valéria Lima

Ângela Maria Endlich

Otávio Cristiano Montanher

Matheus Grochoski Felini

Dispersão da covid-19 no Estado do Paraná

Kelly Cristina Rigoldi

Laine Milene Caraminan

Rafael Balieiro Crestani

Rodrigo Blaudt Lima da Silva

Gabriel Henrique Sorato da Silva

Monique Rafaela Ferreira

Figura 3 - Evolução do número de municípios contaminados

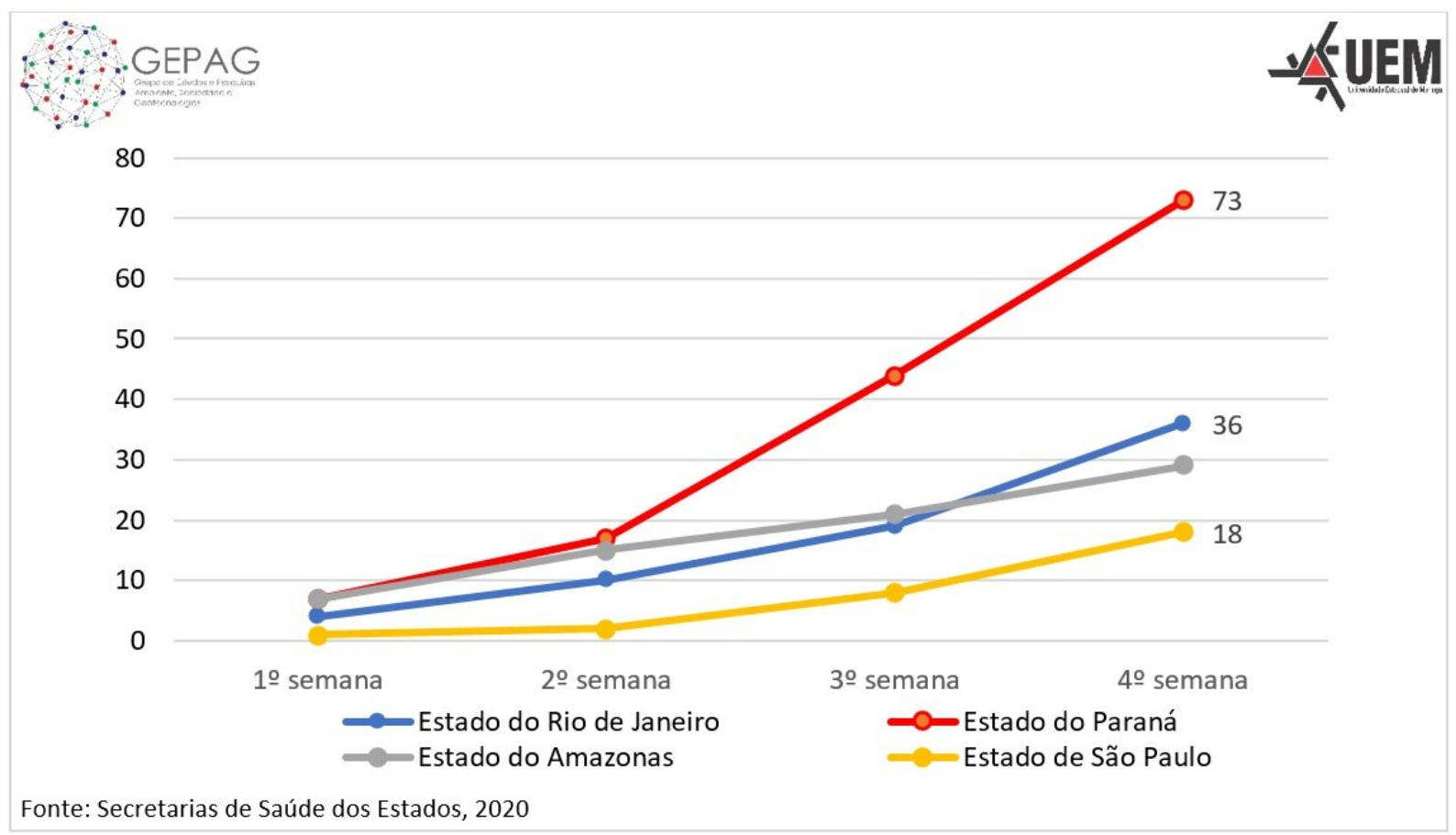

Autores, 2020

Figura 4 - Paraná: Síndrome Respiratória Aguda Grave 2010-2020, no período 12/03 a 12/04

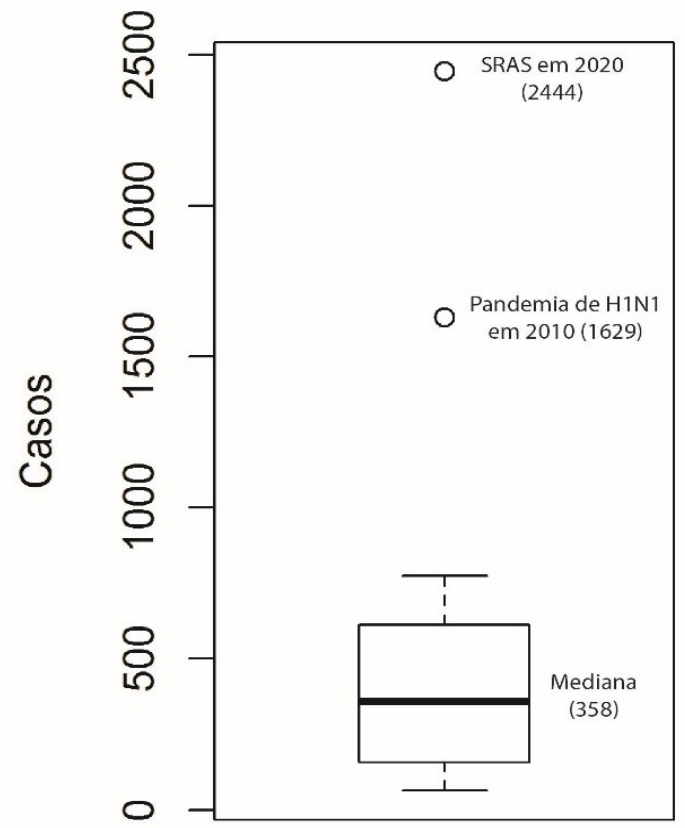

Fonte: Sivep-Gripe/MS, Elaboração: Autores, 2020 
Considerando isso, levanta-se a hipótese de que o vírus esteja mais disseminado pelo território do que indicam os registros oficiais. Uma vez reconhecido que sua dispersão se dá ancorada a à rede de fluxos existentes entre cidades, o estudo do IBGE (2008) torna-se um indicador eloquente da capacidade e do papel das cidades médias na contaminação dos pequenos municípios localizados em sua região de influência. Na Figura 5, pode ser visualizada a rede de conexões entre as cidades médias e suas respectivas regiões. No caso do Paraná, são seis: Londrina, Maringá, Cascavel e Foz do Iguaçu, Guarapuava e Ponta Grossa.

Figura 5 - Paraná: casos de Covid-19 em 26/04/2020

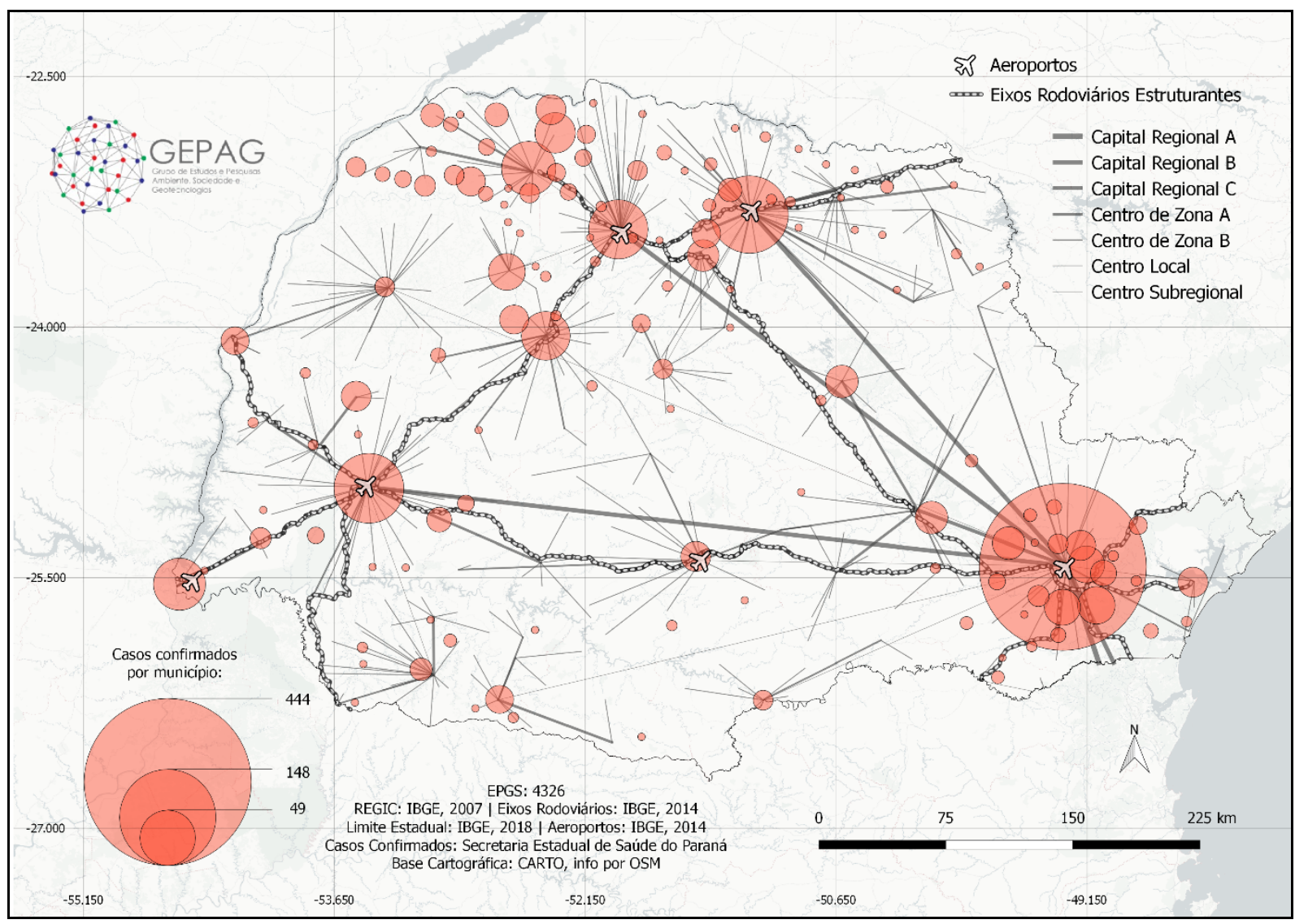

Elaboração: Autores, 2020

A contaminação de vários municípios no noroeste do estado se destaca, formando um aglomerado significativo de casos. Pode ser notada a conexão de grande parte deles com a cidade de Paranavaí. Sua região de influência é a que se encontra mais fortemente afetada em termos relativos, tendo em vista a difusão de casos de contágios originados em uma unidade industrial cuja empregabilidade tem abrangência regional. Como tão bem afirmara Veltz (1996), por regra, o emprego é mais concentrado que a população. Isso não é uma especificidade de áreas metropolitanas. Grandes plantas industriais, como a da GTFoods, com expressividade regional, são pontos de significativos fluxos da considerada mobilidade pendular do trabalho, portanto têm alto potencial para contaminar os municípios da região. 
Pessoas de diversas pequenas localidades da região foram afetadas, no âmbito da $14^{\mathrm{a}}$ Regional de Saúde, polarizada por Paranavaí, única área do Paraná que figura dentro da média nacional, mas com incidência superior as demais partes desta unidade federativa, que de acordo com os dados oficiais, estão abaixo dessa média nacional.

A epidemia de Covid-19, como qualquer fenômeno condicionado pelas estruturas espaciais preexistentes, não acontece do mesmo modo para todas as regiões. Sabendo disso, fazemos, a seguir uma breve análise olhando para as macrorregiões de saúde do Paraná.

\section{A SITUAÇÃO EPIDEMIOLÓGICA NAS MACRORREGIÕES DE SAÚDE DO ESTADO DO PARANÁ}

O estado do Paraná é divido em seis macrorregiões de saúde: Leste, Campos Gerais, Norte, CentroSul, Noroeste e Oeste. A observação dos momentos iniciais da difusão do vírus, por várias razões que exigem mais pesquisas, revelou impactos diferenciados entre as regiões.

Tabela 1 - Paraná: Situação epidemiológica nas macrorregiões de saúde, 12/04/2020

\begin{tabular}{|l|c|c|c|c|c|c|}
\hline Macrorregião & Municípios & Casos & Mortes & $\begin{array}{c}\text { Munícipios } \\
\text { Infectados }\end{array}$ & $\begin{array}{c}\text { \% Municípios } \\
\text { Infectados }\end{array}$ & $\begin{array}{c}\text { Letalidade } \\
(\%)\end{array}$ \\
\hline Noroeste & 113 & 97 & 12 & 17 & 51,51 & 12,37 \\
\hline Norte & 99 & 101 & 07 & 17 & 17,17 & 6,95 \\
\hline Oeste & 79 & 120 & 02 & 11 & 13,92 & 1,67 \\
\hline Centro-Sul & 35 & 10 & 00 & 07 & 20,00 & 0,00 \\
\hline Campos Gerais & 38 & 17 & 00 & 05 & 13,16 & 0,00 \\
\hline Leste & 35 & 393 & 09 & 21 & 60,00 & 2,29 \\
\hline
\end{tabular}

Fonte de dados: Secretaria Estadual de Saúde; Elaboração: Autores, 2020

A Tabela 1, por exemplo, permite verificar que a letalidade (casos confirmados/óbitos) da Covid-19, estava muito mais elevada na região noroeste, que, como vimos na Figura 1, forma um aglomerado de municípios infectados e com muitos casos. Enquanto na Macrorregião Leste, onde está a Região Metropolitana de Curitiba, a letalidade era de 2,29\%, na Macrorregião Noroeste era de 12,37\%.

Alguns fatores revelam uma situação mais crítica na macrorregião noroeste do Estado:

1. O estudo do IBGE sobre a acessibilidade, classificou 61 municípios como remotos. São municípios que, na escala estadual, possuem as maiores dificuldades para acessar as capitais regionais e, portanto, também os serviços de saúde. Destes, 32 estão na Macrorregião Noroeste, ou seja, mais da metade, conforme se vê na Figura 1.

2. O Oeste do estado do Paraná possui as maiores taxas de envelhecimento, portanto, maiores proporções de sua população sujeitas a desenvolver as formas mais graves da doença. Enquanto as Macrorregiões Leste e Campos gerais possuem taxas médias de envelhecimento de 6,79\%, as Macrorregiões Noroeste e Oeste são de 9,38\%.

3. Falta aos pequenos municípios, mais idosos e com maiores dificuldades de acesso aos centros regionais, respiradores e leitos de UTI. Nessa macrorregião, $78 \%$ não têm leitos de UTI e 45\% não possui nenhum tipo de leito.

As principais cidades, tão logo começaram a registrar os primeiros casos de Covid-19, tomaram medidas para restringir a circulação de pessoas e reduzir a velocidade de difusão do vírus. Entretanto, os efeitos econômicos das decisões tomadas pelas autoridades locais resultaram em tensões com os agentes econômicos locais que pressionaram pelo afrouxamento das medidas de restrição à circulação, como, por exemplo, o fechamento de serviços comerciais não essenciais. DOl:http://dX.doi.org/ 10.14393/Hygeia0054619 Hygeia Edição Especial: Covid-19, Jun./2020 p.251-262, pág.260 
Consequentemente, no final do segundo mês de circulação viral, assistiu-se a uma redução das taxas de isolamento social, que pode acelerar a progressão do número de casos, por um lado, e, por outro, favorecer a contaminação dos pequenos municípios, uma vez que eles estão estreitamente conectados com cidades médias como Maringá, Londrina, Ponta Grossa, Cascavel, Guarapuava e Foz do Iguaçu. Em outras palavras, o que for decidido nessas cidades determinará o que ocorrerá nas cidades sobre sua influência. O agravamento simultâneo dos casos nas cidades médias paranaenses e nas cidades pequenas poderá representar dificuldades ao sistema de saúde de toda a região.

\section{CONCLUSÃO}

É importante registrar que essa breve análise trata de modo ainda preliminar e, portanto, insuficiente, do processo de difusão de Covid-19 pelo estado do Paraná. Basta lembrar que no começo do mês de maio de 2020, ainda não se chegou à fase mais aguda da crise. De modo geral, o vírus ainda não chegou à metade dos municípios brasileiros e, também, ainda não atingiu significativamente os mais pobres. Nas grandes metrópoles brasileiras, especialmente São Paulo e Rio de Janeiro, isso começa a acontecer. Os efeitos desse processo serão muitos e demandará a continuidade de análises e o desenvolvimento de pesquisas.

Entretanto, a análise feita aqui, tomando como referência o estado do Paraná, permite fazer algumas constatações:

4. A difusão do vírus é moldada pelas formas e processos espaciais.

5. O fluxo intenso de pessoas entre as cidades médias e o exterior permitiu que rapidamente o vírus se interiorizasse. Não prescindiu, portanto, da instalação da fase de transmissão comunitária nem na capital paulista, nem na capital paranaense, posicionadas hierarquicamente acima das cidades médias.

6. A rede de relações das cidades médias com sua região é um fator fundamental para a dispersão do vírus para as pequenas cidades. $O$ que for decidido nelas terá implicações para toda a região e, em revanche, afetará os serviços de saúde nelas sediados.

7. Os serviços de saúde são muito frágeis nas cidades pequenas. A maioria não tem leitos UTI disponível. Mais da metade não tem nenhum tipo de leito. Em alguns falta até mesmo profissionais de saúde. O pico da crise epidemiológica, se ações assertivas não forem adotadas, terá maior impacto sobre elas, pois pode não haver recursos para atender a todas as demandas.

8. Municípios considerados remotos poderão ter problemas ainda maiores devido às distâncias em relação às cidades com estrutura hospitalar para atendimento de casos de Covid- 19 . Possivelmente serão as últimas a serem atingidas e demandarão atenção no pior momento da crise.

A organização do sistema de saúde precisa se antever a esses cenários e garantir que nenhum cidadão padecerá sem o devido atendimento. Muitas variáveis desse cenário já eram conhecidas. $\mathrm{A}$ ausência ou a insuficiência de equipamentos e serviços de saúde, diante da pandemia da Covid-19, entretanto, ganham agora maior evidência neste momento e, podem ser mais bem equacionadas para o enfrentamento não somente das condições do momento, mas, também, para amenizar as precariedades, de longa data, do sistema de saúde dos pequenos municípios

A presente análise fornece alguns indicativos dos pontos e das rotas de dispersão de doenças de alta capacidade de contágio, que podem ser levados em conta quando da ocorrência de eventos de saúde similares. Focar atenção nesses pontos e rotas, articulando agentes para dar respostas coordenadas pode ser uma estratégia de bons resultados na contenção de processos pandêmicos e epidêmicos. 


\section{REFERÊNCIAS}

BRASIL. Ministério da Saúde. Doença pelo coronavírus 2019. Boletim Epidemiológico (Especial), Brasília, v. 07, abr./2020.

IBGE (INSTITUTO BRASILEIRO DE GEOGRAFIA E ESTATÍSTICA). Região de Influência das cidades. IBGE: Rio de Janeiro, 2008.

IBGE (INSTITUTO BRASILEIRO DE GEOGRAFIA E ESTATÍSTICA). Acessibilidade Geográfica dos Municípios. IBGE: Rio de Janeiro, 2018.

KOSIK, K. Dialética do concreto. 7. ed. São Paulo: Paz e Terra, 2002.

LUKAKS, G. Ontologia do ser social I. 2. ed. São Paulo: Boitempo, 2018.

MARTINUCI, O. S. Cartografias da saúde: alguns apontamentos. In: RIBEIRO, E. A. W. (org.). A cartografia na geografia da saúde. Blumenau: IFC, 2019, p. 6-21. https://doi.org/10.21166/9788556440433cap1

SANTOS, M. Espaço e método. Edusp: São Paulo, 2014.

SANTOS, M. Por uma geografia nova. Edusp: São Paulo, 2004.

SANTOS, M. A natureza do espaço. Edusp: São Paulo, 2002.

SANTOS, M. O papel ativo da Geografia. Revista Território, Rio de Janeiro, v. 5, n. 9, p. 103-109, 2000.

SNOW, J. Sobre a maneira da transmissão da cólera. São Paulo: Hucitec, 1999.

SPOSITO, M. E. B. (org.). Cidades médias. São Paulo: Expressão Popular, 2007. 